\title{
Kangaroo Mother Care for Low Birth Weight Babies: A prospective Observational Study
}

\author{
Subedi K $\mathbf{K}^{1}$, Aryal DR ${ }^{2}$, Gurubacharya $\mathrm{SM}^{3}$ \\ ${ }^{1}$ Dr. Kalpana Subedi, Consultant Pediatrician, ${ }^{2}$ Dr. Dhana Raj Aryal, Chief Consultant Pediatrician, ${ }^{3}$ Dr. Simmi Misra \\ Gurubacharya, Registrar, All from Paropakar Maternity and Women's Hospital, Thapathali, Kathmandu, Nepal.
}

Address for Correspondence: Dr. Kalpana Subedi. E-mail:kalpana_subedi@hotmail.com

\begin{abstract}
Introduction: Kangaroo Mother Care is the low cost, humane technique for caring low birth weight babies by direct skin to contact with the mother. Objective: The Prospective observational study was done to see the effect of KMC especially on weight gain on low birth weight babies weighing 2000 grams or less at Special Care Baby Unit of Paropakar Maternity and Women's hospital, Kathmandu. Method: The study was conducted in Special Care Baby Unit (SCBU) of Paropakar Maternity and Women's Hospital over 7 months period May 2007 to Nov. 2008 (from Baishakh 2064 to Kartik 2065). The method of care consisted of skin to skin contact between the mother and the infant. Result: It was observed that babies had good weight gain of average $30 \mathrm{gms}$ /day and had short duration of hospital stay of average 9 days. Babies had less morbidities like hypothermia, apnea, skin infections and oral thrush.100\% babies had exclusive breast feeding and KMC was acceptable to mothers. Conclusion: Kangaroo Mother Care shows early and good weight gain in low birth weight babies. It is simple, low cost technique and well acceptable by mother and family and can be continued at home.
\end{abstract}

Key words: Kangaroo mother

\section{Introduction}

Kangaroo mother care (KMC) is the term given to a method where baby is kept in direct skin to skin contact with the mother. This is humane, low cost technique for care of low birth weight (LBW) babies. Other advantages of $\mathrm{KMC}$ include exclusive breast feeding, good mother and infant bonding. Despite the various advantages of KMC, it is not widely practiced in Nepal for caring of LBW babies. In Paropakar Maternity and Women's Hospital, Thapathali, four bedded KMC ward has been established for caring LBW babies by KMC method.

\section{Material and Method}

This is a prospective observational study conducted in Special Care Baby Unit(SCBU) of Paropakar Maternity and Women's Hospital over 7 months period May 2007 to Nov. 2008 (from Baishakh 2064 Kartik to 2065). The study included 60 low birth weight neonates of weight 2000 grams or less. Critically ill babies requiring neonatal intensive care unit (NICU) and those mothers who were critically ill or refused for
KMC were excluded. All babies delivered in Maternity Hospital, which were of 2000 grams and less were admitted to Special Care Baby Unit. Unstable babies were managed in NICU or SCBU. Stable babies were elected for KMC. Sick LBW babies after management of primary illness were also included in the study. LBW babies requiring intravenous or oral medication after initial stabilization were also included. Mothers and at least one family member were explained about methods and advantages of KMC and were motivated. All the babies admitted in KMC ward were given 24 hours continuous $\mathrm{KMC}$, even during night. Babies were removed from mother's chest during breast feeding, changing diapers and during mother's personal works. Babies were weighed naked on an electronic weighing machine (Phoenix with weighing scale accuracy of $+/$ $10 \mathrm{gms}$ ) on admission in KMC and daily during morning hours till discharge. All babies were exclusively breast fed and those who were not sucking adequately were given expressed breast milk (EBM) with spoon. All babies were monitored daily for any signs of infection/ sepsis, breast feeding, jaundice and weight gain. Babies 
with suspected or confirmed sepsis, hyperbillirubinemia requiring phototherapy were temporarily withdrawn from KMC and transferred to SCBU or NICU. Babies were discharged when they showed a weight gain of minimum $10 \mathrm{gm} / \mathrm{kg} /$ day for at least three consecutive days, were stable and maintaining vitals, not showing any signs of sepsis and mothers were confident and comfortable for caring babies at home. On discharge, they were advised for follow- up every week till babies reached to 2500grams. Mothers were counseled about the danger signs during the stay in $\mathrm{KMC}$ ward. At the time of discharge, they were advised to bring the babies immediately if they find any danger signs in babies. The major outcome measure was weight gain. Secondary measures included duration of hospital stay, morbidity and mortality.

\section{Result}

In this observational study, 85 neonates were enrolled but the effect of KMC was observed only in 60 babies as 25 did not fulfill the criteria. Out of 25 babies, 22 babies were excluded from the study because mother or family members of the babies refused to stay in the hospital till discharge criteria. Most of those excluded were discharged on request after one or two days after admission in KMC ward as mother became confident to handle the baby and wanted to continue KMC at home. Three babies shifted to NICU later expired. First baby who was of 34 weeks gestation and birth weight $1400 \mathrm{Grams}$ was started KMC after 24 hours observation in SCBU, developed features of sepsis on $4^{\text {th }}$ day of KMC. Second baby was of 32 weeks of gestational age, birth weight 1800 grams, was stable for 72 hours and KMC started on D4 of life but had to transfer back to NICU because of opening of ductus arteriosus on the same evening. Third baby was of 32 weeks of gestational age and birth weight 1360 grams was not gaining weight till day 9 of KMC. On day 10 , developed hypoglycemia and features of sepsis.
Among 60 babies included for study, 37 (61.67\%) were female and $23(38.33 \%$.) were male. The weight of the babies were ranged between 1200 grams to 2000 grams and $50 \%$ of total included babies had weight more or equal to 1800 grams(Table I). According to gestational weight, majority (48\%) of the babies were of more than 37 weeks(Table II) All babies were classified according to Lubchenco's charts in three groups, in which preterm appropriate for gestational age (AGA) were 26 (43.33.\%), preterm small for gestational age (PT SGA) were $5(8.33 \%)$ and term small for gestational age (TSGA) were 29(48.33\%). As shown in Table III, Term SGA started to gain weight earlier (average duration 3.27 days) than the other groups but high average weight gain/day was observed in preterm SGA group (Table IV). In this study, we observed and analysed also the duration of stay at KMC, total hospital stay and morbidities in AGA, PT SGA and T SGA groups (Table V-VII).

Table I: Birth Weight Groups.

\begin{tabular}{|l|c|c|}
\hline Groups (in grams) & No. & \% \\
\hline $1200-1399$ & 3 & 5 \\
\hline $1400-1599$ & 13 & 21.7 \\
\hline $1600-1799$ & 14 & 23.3 \\
\hline$=/>1800$ & 30 & 50 \\
\hline Total & $\mathbf{6 0}$ & $\mathbf{1 0 0}$ \\
\hline
\end{tabular}

Table II: Gestational Assessment Groups.

\begin{tabular}{|l|c|c|}
\hline Gestational age & No. & \% \\
\hline$<32$ weeks & 11 & 18.3 \\
\hline $33-34$ weeks & 10 & 16.7 \\
\hline $35-36$ weeks & 10 & 16.7 \\
\hline$>37$ weeks & 29 & 48.3 \\
\hline Grand total & $\mathbf{6 0}$ & $\mathbf{1 0 0}$ \\
\hline
\end{tabular}

Table III: Average Duration When Weight Gain Started In Different Groups.

\begin{tabular}{|l|c|c|c|}
\hline Groups & \multicolumn{3}{|c|}{ Duration in days } \\
\hline & Minimum & Maximum & Average \\
\hline Preterm AGA $(\mathrm{n}=26)$ & 2 & 8 & 4 \\
\hline Preterm SGA $(\mathrm{n}=5)$ & 2 & 5 & 3.4 \\
\hline Term SGA $(\mathrm{n}=29)$ & 2 & 7 & 3.27 \\
\hline
\end{tabular}

Table IV: Average Weight Gain/Day in Different Age Groups.

\begin{tabular}{|l|c|c|c|}
\hline \multirow{2}{*}{ Groups } & \multicolumn{3}{|c|}{ Weight Gain/Day In grams } \\
\cline { 2 - 4 } & Minimum & Maximum & Average \\
\hline Preterm AGA $(\mathrm{n}=26)$ & 10 & 50 & 26.50 \\
\hline Preterm SGA $(\mathrm{n}=5)$ & 10 & 50 & 34.60 \\
\hline Term SGA $(\mathrm{n}=29)$ & 10 & 50 & 29.96 \\
\hline
\end{tabular}


Table V: Duration of Stay in KMC Room.

\begin{tabular}{|l|c|c|c|}
\hline \multirow{2}{*}{ Groups } & \multicolumn{3}{|c|}{ Duration in Days } \\
\cline { 2 - 4 } & Minimum & Maximum & Average \\
\hline Preterm AGA $(\mathrm{n}=26)$ & 3 & 10 & 5.996 \\
\hline Preterm SGA $(\mathrm{n}=5)$ & 4 & 9 & 6.200 \\
\hline Term SGA $(\mathrm{n}=29)$ & 3 & 11 & 5.448 \\
\hline
\end{tabular}

Table VI: Total Hospital Stay.

\begin{tabular}{|l|c|c|c|}
\hline Groups & \multicolumn{3}{|c|}{ Duration in days } \\
\hline & Minimum & Maximum & Average \\
\hline Preterm AGA $(\mathrm{n}=26)$ & 5 & 26 & 10.333 \\
\hline Preterm SGA $(\mathrm{n}=5)$ & 5 & 11 & 8.200 \\
\hline Term SGA $(\mathrm{n}=29)$ & 3 & 19 & 8.448 \\
\hline
\end{tabular}

Table VII. Morbidities

\begin{tabular}{|l|c|c|}
\hline Opening of PDA causing CCF & 1 & $1.6 \%$ \\
\hline Hypoglycemia & 1 & $1.6 \%$ \\
\hline Sepsis & 3 & $4.7 \%$ \\
\hline Neonatal jaundice & 4 & $6.3 \%$ \\
\hline Minor illnesses- oral thrush, skin pustules etc. & 6 & $9.5 \%$ \\
\hline
\end{tabular}

\section{Discussion}

Kangaroo mother care has been proposed as an alternative method for caring low birth weight neonate. The method was first implemented by Roy and martinez in 1979 at Maternal and Child Institute of of Bogota, Colombia .It consists skin to skin contact, exclusive breast feeding and early discharge. ${ }^{1,2}$ In Nepal few, institutes have adopted this technique to care low birth weight babies. Because of loss of extra cellular fluid, around $5-15 \%$ of weight loss occurs in newborn babies. The nadir of weight loss occurs by 4-6 days of life and then gradually weight gain starts and birth weight regained by 14-21 days of life. ${ }^{3}$ Our discharge criteria for LBW babies were weight gain of at least 10 grams/ $\mathrm{kg}$ body weight/day for three consecutive days. So, we could not confirm when the birth weight regained but average duration needed when weight gain began after starting $\mathrm{KMC}$ was 3-4 days in different groups.

Various other studies had shown that KMC babies had better average weight gain per day. A study done by Suman Rao et al. from Mumbai India showed average weight gain of 23,99 grams in KMC groups. ${ }^{4}$ Similarly, experience of Gupta M. et al. from Rajasthan India, showed average weight gain of 21.3 grams/day and $\mathrm{K}$. Ramanathan, V.K.Paul et al.from Delhi found average weight gain in KMC babies after first week of life were $15.9 \mathrm{gm} /$ day. ${ }^{\mathbf{5 , 6}}$ In our study, we found average weight gain of 30.35 gms/day. Gupta M, Jora R et al observed mean duration of hospital stay was 15.5 days. ${ }^{5}$ Similarly, KMC in infants in Merida had discharged at 13.4 days after enrolment. ${ }^{7}$ In Delhi studies average day of hospital stay was $27.2+-7$ days. $^{6}$ In our study, average duration of hospital stay was 8.99 days.
Kangaroo mother care promotes exclusive breast feeding, ensures temperature maintenance, decrease neonatal morbidities. ${ }^{8}$ Hypothermia was significantly less common (13.5 vs. 31.5 episodes/100 infants) in KMC infants in Merida. ${ }^{7}$ These findings were supported by our study also as all the babies were exclusively breast fed, there was single episode of hypoglycemia and there were less sepsis and apnea.Three babies in our study expired after enrolment in $\mathrm{KMC}$, one due to $\mathrm{CCF}$ following opening of PDA and two babies due to sepsis, however these causes are not directly related to KMC. Conde-Agudelo A, Diaz-Rossello JL et al. found no evidence in difference in infant mortality in $\mathrm{KMC}$ as compared to conventional care after stabilisation. ${ }^{9}$

\section{Conclusion}

We conclude that $\mathrm{KMC}$ is useful method of caring LBW baby in respect of early weight gain in our set up. Other advantages of this technique are low cost, promotes exclusive Breast feeding practice and increases mothers confidence in handling small babies and builds good mother and infant bonding. As the sample size in our study is small (60 Neonates) and the study was non comparative, a future study with large sample size and comparative study between $\mathrm{KMC}$ and Conventional Method of Care of LBW baby, is necessary to observe more reliable effect on weight gain and morbidity.

\section{Acknowledgement}

Authors would like to express their gratitude to all the staffs of the baby unit and $\mathrm{KMC}$ ward and also to the mothers and their babies who participated in this study. We would also like to thank the research committee of the hospital for allowing us to publish the article. 


\section{References}

1. Whitelaw A, Sleath K. Myth of Marsupial Mother; Home Care of very Low Birth Weight Babies, in Bogota, Columbia. Lancet 1985; 25: 1206-1208.

2. Charpak N, Figueroa Z. Kangaroo Mother Care Programme Practical Rules. Bogota, Columbia: Kangaroo Foundation; 2001.

3. Dierdre Ellard, Diane M Anderson; Nutrition in; John P. Cloherty, Eric C. Eichenwald, Ann R.Stark; Manual of Neonatal Care. 6th edition;Lippincott, Williams\&Wilkins,2008,114.

4. Suman RP, Udani R, Nanavati R. Kangaroo Mother Care for Low Birth Weight Infants: A Randomized Controlled Trial. Indian Pediatr 2008;45(1): 17-23.

5. Gupta M, Jora R, Bhatia R. Kangaroo Mother Care (KMC) in LBW Infants- A Western Rajasthan Experience. Indian J Pediatr 2007; 74(8):747-9.
6. Ramanathan K, Paul VK, Deorari AK, Taneja U and George G. Kangaroo Mother Care in Very Low Birth Weight Infants. Indian J Pediatr 2001; 68(11):1019-1023.

7. Cattaneo A, Davanzo R, Worku B, Surjono A, Echeverria M, Bedri A, Haksari E, Osorno L, Gude B, Setyowireni D, Quintero S, Tamburlini G. Kangaroo Mother Care for Low Birth Weight Infants: A Tandomized Controlled Trial in Different Settings. Acta Paediatrica 1998; 87(9): 976-985.

8. Feldman R, Eidelman Al. Intervention Programs for Premature Unfants. Clin Perinatol 1998; 25: 613-626.

9. Conde-Agudelo A, Diaz-Rossello JL, Belizan JM; Kangaroo Mother Care to Reduce Morbidity and Mortality in Low Birthweight Infants; published in The Cochrane Library, Issue 4, 2000. 